\title{
Tracing the boundaries of Cenozoic volcanic edifices from Sardinia (Italy): a geomorphometric contribution
}

\author{
M. T. Melis ${ }^{1}$, F. Mundula ${ }^{1}$, F. Dessì ${ }^{1}$, R. Cioni $^{2}$, and A. Funedda ${ }^{1}$ \\ ${ }^{1}$ Department of Chemical and Geological Sciences, University of Cagliari, Cagliari, Italy \\ ${ }^{2}$ Department of Earth Sciences, University of Firenze, Firenze, Italy \\ Correspondence to: M. T. Melis (titimelis@ unica.it)
}

Received: 27 April 2014 - Published in Earth Surf. Dynam. Discuss.: 28 May 2014

Revised: 1 September 2014 - Accepted: 3 September 2014 - Published: 25 September 2014

\begin{abstract}
Unequivocal delimitation of landforms is an important issue for different purposes, from sciencedriven morphometric analysis to legal issues related to land conservation. This study is aimed at giving a new contribution to the morphometric approach for the delineation of the boundaries of volcanic edifices, applied to 13 monogenetic volcanoes (scoria cones) related to the Pliocene-Pleistocene volcanic cycle in Sardinia (Italy). External boundary delimitation of the edifices is discussed based on an integrated methodology using automatic elaboration of digital elevation models together with geomorphological and geological observations. Different elaborations of surface slope and profile curvature have been proposed and discussed; among them, two algorithms based on simple mathematical functions combining slope and profile curvature well fit the requirements of this study. One of theses algorithms is a modification of a function introduced by Grosse et al. (2011), which better performs for recognizing and tracing the boundary between the volcanic scoria cone and its basement. Although the geological constraints still drive the final decision, the proposed method improves the existing tools for a semi-automatic tracing of the boundaries.
\end{abstract}

\section{Introduction}

Unequivocal delimitation of landforms is a general objective that needs to be pursued for different purposes, both scientific, such as the morphometric analysis of a given set of landforms, and applicative, such as the conservation of the natural heritage. The continuously increasing capability of digital elaboration of the DEM (digital elevation model) data gives now the possibility of adopting tools for the automatic recognition and delimitation of specific landforms, and these tools are important for obtaining objective results that are not heavily dependent on the subjective choices of an operator. This assumes particular importance when the delimitation of a given landform is required for conservation purposes, where the delimited area is to be subject to specific regulations or laws. The improvement of objective and reproducible methods to delimitate the external perimeter of a landform, thereby reducing to a minimum the subjective choices of an operator, is very important especially if the results are to be used for applying regulations.
The morphological and morphometric characteristics of volcanic landforms and edifices have been the subject of studies since the end of the 1970s (e.g. Pike, 1978; Pike and Clow, 1981; Wood, 1980a, b), and overall reviews of the typical values of elevation, base diameter, crater diameter and average slope, and of their variability, are now available (e.g. Francis, 1993; Ollier, 1988; Cas and Wright, 1987; Thouret, 1999; Walker, 2000; Fink and Anderson, 2000). These studies have been largely used to define the main morphometric parameters of different types of volcanic edifices, and such parameters have been used to discuss and infer their origin, degradation and also age (e.g. Kereszturi et al., 2013). Conversely, to the best of our knowledge, none of the existing studies on volcanic edifice morphometrics have been used for conservation purposes up to now.

As the term volcanic landform is often used with a general meaning to indicate all the surface forms related to volcanic activity, we prefer in the following to use the more specific term "volcanic edifice" to refer to all those landforms 
formed by accumulation of products around the volcanic vent, whether during a single event or as the cumulated result of multiple eruptions. Volcanic edifices largely vary in type and scale: they can be constructional, such as monogenetic pyroclastic cones and lava domes at small scale, or composite volcanic massifs and shield volcanoes at large scale, or can be destructional/excavational, such as maars, craters or calderas. Consequently, the external boundary of these edifices can have largely variable sizes and shapes. In this sense, the simplest volcanic edifice is represented by a symmetric, cone-shaped pile of products built upon a planar surface. In this case the edifice boundary is circular and represented by the concave break in slope at its base (Euillades et al., 2013). Obviously, this represents an extremely simplified, somewhat theoretical, case rarely present in nature.

In their interesting review of volcanic edifice morphometrics, Grosse et al. (2012) discussed how, before the advent of DEMs, the process of delimitation of volcanic edifices, mainly pursued for studies on volcano morphometry, was based on the integrated analysis of topographic maps and air photos with field measurements. Following the large use of DEM, delimitation of volcanic edifices, mainly scoria cones, has been manually performed on the basis of shaded relief images and slope maps (e.g. Fornaciai et al., 2012); the use of dedicated algorithms for semi-automatic and automatic delimitation of volcanic edifices has been recently developed (Grosse et al., 2009, 2012; Euillades et al., 2013). Many authors have used these data for obtaining descriptive morphometric parameters (e.g. base diameter, crater elongation, cone height), or for discussing the relationships between volcanic and tectonic structures (e.g. location of depressions on the crater rim, alignment of cones, azimuths and geometry of the fracture feeding system; Tibaldi, 1995; Mazzarini et al., 2010). The studies of Hooper and Sheridan (1998), Carn (2000) and Kereszturi et al. (2012) analysed the morphometric characteristics of scoria cones in order to estimate possible relationships with their age and to evaluate the extent of erosional processes.

In the framework of the application of Article 142 of the Italian "Cultural Heritage and Landscape Code", Legislative Decree 42/2004, which states that volcanoes are areas protected by law, a detailed study aimed at identifying and delimiting Cenozoic volcanic edifices present in Sardinia was performed. In order to delimit these areas, a comprehensive morphological, volcanological and morphometrical study was undertaken, proposing a methodology based on the semi-automatic delimitation of the volcanic edifices using a DEM, largely overcoming the subjectivity related to traditional techniques.

In the first phase of this study, a landform classification was used, based on local morphometric attributes such as slope gradient and total curvature (Shary, 1995; Shary et al., 2002; Florinsky, 2012). The results, discussed below, were generally useful to recognize the landforms, but they proved to be unsatisfactory for the identification of their boundaries, as the use of a sole slope classification can hardly represent the morphologic heterogeneity of a complex set of scoria cones at the regional scale. Therefore, the study was implemented by using the methodology proposed by Grosse et al. (2012), mainly based on two additional geomorphometric parameters (slope and profile curvature), integrated with the use of a new - modified Grosse - methodology, presented and discussed in detail in the following.

\section{Objectives and methods}

The main objective of the research was the recognition, selection and delimitation of well-preserved volcanic edifices from the Cenozoic volcanic activity of Sardinia (Italy). The result of this process can then be used by the regional authority for adopting conservation measures and to establish development and management policies over the selected landforms. In the present section we present a short geological framework of the Cenozoic volcanism of Sardinia and the methods adopted in the study. In the following sections, we discuss in detail the morphometric approaches used to get a final delimitation of the selected areas, together with some key examples, which well illustrate the different problems encountered in the research.

Figure 1 is a flow chart showing the general approach adopted in the study.

\subsection{Geological setting and volcanic landforms}

During the Cenozoic, Sardinia was subject to two distinct volcanic cycles: the Oligocene-Miocene calc-alkaline cycle (32-15 Ma; Lecca et al., 1997) and the Plio-Pleistocene alkaline and tholeiitic cycle (5.1-0.1 Ma; Beccaluva et al., 1985), whose starting phase was recently reconsidered as being of the Messinian age (6.6-6.4 Ma; Lustrino et al., 2007) (Fig. 2, Table 1). The Pliocene-Pleistocene activity, whose products are largely dispersed in Sardinia, was mainly basaltic in composition, varying from mildly to strongly alkaline (mostly with sodic character) to sub-alkaline (with tholeiitic affinity), and shows a marked within-plate geochemical signature (Lustrino et al., 1996, 2000, 2002). Eruptive centres are mainly located, and in some cases aligned, on the main $\mathrm{N}-\mathrm{S}, \mathrm{N} 60$ and N90 structures. A wide range of landforms are associated with the Pliocene-Pleistocene volcanic cycle, mainly represented by extended lava fields, monogenetic volcanoes and minor compound volcanoes. Monogenetic volcanoes are mainly represented by scoria cones, distributed in the Logudoro (north-west Sardinia; Beccaluva et al., 1981), in the Orosei-Dorgali areas (central-eastern Sardinia; Lustrino et al., 2002) and in central Sardinia (Giare). PliocenePleistocene scoria cones span a time interval from $3.0 \pm 0.1$ to $0.11 \pm 0.02 \mathrm{Ma}$ (Beccaluva et al., 1985). A set of wellpreserved scoria cones from the Plio-Pleistocene activity is here presented in detail. They range from nearly unmodified, poorly eroded cones, characterized by about $30^{\circ}$ sloping 

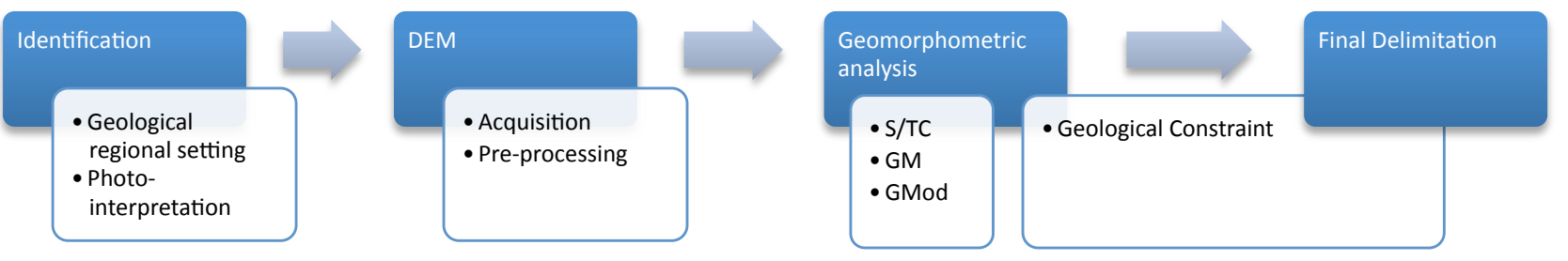

Figure 1. Schematic flow chart of the proposed methodology for the delimitation of the boundaries of the volcanic edifices with the three morphometric classifications discussed in the text.

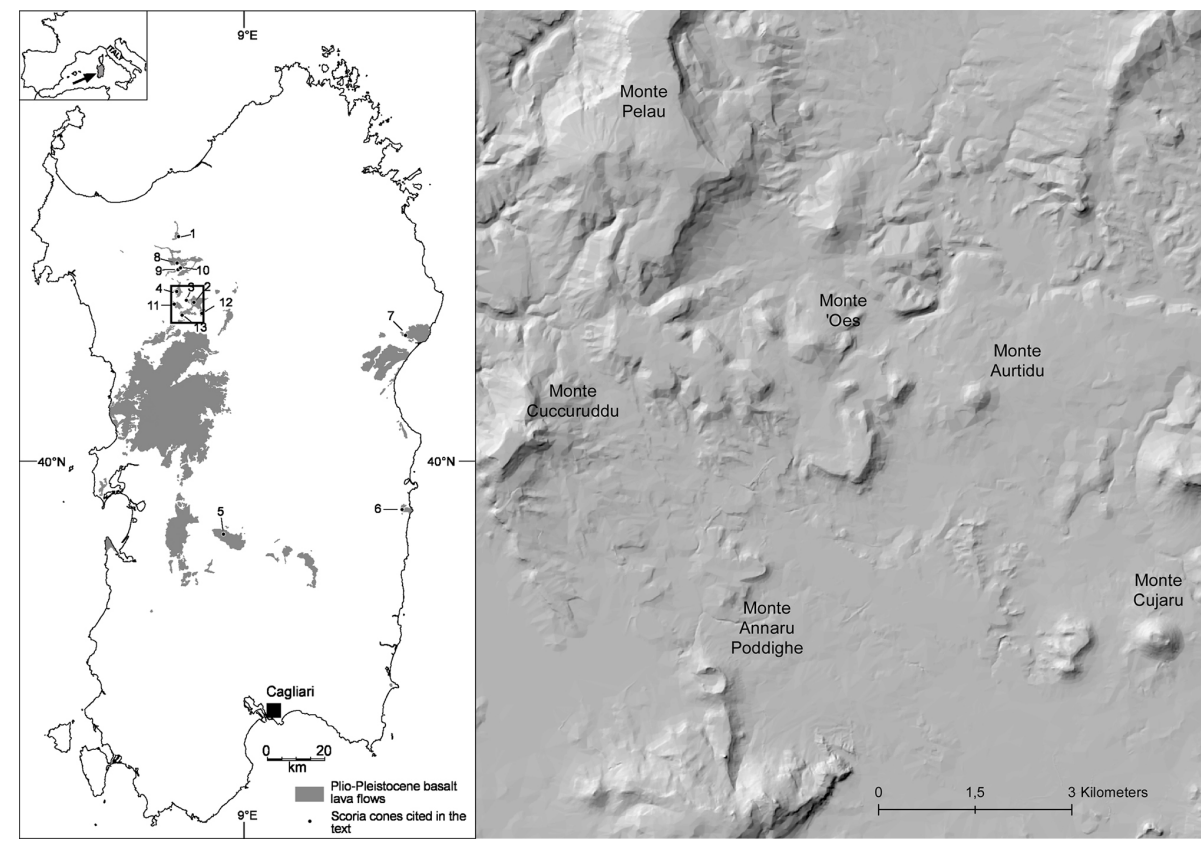

Figure 2. Distribution of Plio-Pleistocene basalt lava flows in Sardinia and localization of the scoria cones (the codes are referred to the list in Table 1). The hillshade view represents the area in the box with high concentrations of volcanic edifices.

flanks (Monte Cujaru; Fig. 3), to quite completely eroded remnants where only the conduit zone, occupied by a neck or a dike of coherent magma, is still preserved. Scoria cones were built up on different palaeo-topographic surfaces, from planar horizontal or gently dipping (as in the cases respectively of Monte Cujaru and Ibba Manna) to highly irregular surfaces (Monte Annaru Poddighe; Fig. 6), laying on scarps a few tens of metres high. Some scoria cones and the related lava fields experienced different degrees of relief inversion, occupying highlands extending a few or tens of square kilometres and elevated from tens to hundreds of metres above the surrounding valleys. Finally, all the scoria cones present different products related to a complex constructional activity, such as lava effusions from the flanks or from the base, lateral collapses related to lava effusion and variable presence of agglutinated scoria banks. These processes reflect the different amount and distribution of volcanic lithofacies in each scoria cone, determining the final morphological features.

\subsection{Identification of scoria cones}

The localization and classification of the volcanic edifices was achieved by integrating data from the scientific literature (e.g. Carmignani et al., 2008; Lustrino et al., 2004, and references therein) with an overview of airborne imagery (photo archives of $1968(\mathrm{~b} / \mathrm{w})$ and 1977 (colour) respectively at the scale of $1: 23000$ and $1: 10000$ ), orthophotos (http://www. sardegnageoportale.it/navigatori/fotoaeree.html) and web 3D digital models (Google Earth and Sardegna 3-D). This analysis allowed the identification of volcanic edifices as scoria cones, small shields or domes, and of the related relict forms and products as craters, necks, dikes, lava flows, debris flow deposits and coulees. Selection of the volcanic edifices to be studied and delimited was mainly based on this step.

\subsection{DEM pre-processing}

A DEM, processed in 2011, with $10 \mathrm{~m}$ pixel resolution and a vertical and horizontal accuracy of $2.5 \mathrm{~m}$, was used for 
Table 1. List of the scoria cones analysed with the basal area and the radiometric age.

\begin{tabular}{lllcccl}
\hline Code & Name & Loc. & $\begin{array}{c}\text { Lat. } \\
\text { centroid }\end{array}$ & $\begin{array}{c}\text { Long. } \\
\text { centroid }\end{array}$ & $\begin{array}{c}\text { Area } \\
\left(\mathrm{km}^{2}\right)\end{array}$ & $\begin{array}{l}\text { K/Ar age } \\
(\mathrm{Ma})\end{array}$ \\
\hline 1 & Monte Massa & Ploaghe & 1478090 & 4507120 & 0.34 & $0.38 \pm 0.04$ \\
2 & Monte Aurtidu & Torralba & 1483410 & 4484150 & 0.27 & $0.4 \pm 0.1$ \\
3 & Monte'Oes & Torralba & 1480750 & 4484890 & 0.29 & $0.4 \pm 0.2$ \\
4 & Monte Pelau & Thiesi & 1477390 & 4487950 & 1.22 & $1.9 \pm 0.1$ \\
5 & Zeppara Manna & Genoni & 1493740 & 4403420 & 0.58 & $2.76 \pm 0.11$ \\
6 & Ibba Manna & Bari Sardo & 1555870 & 4411920 & 0.17 & \\
7 & Punta Su Nurtale & Onifai & 1557160 & 4472680 & 0.16 & \\
8 & Monte Pubulena & Ploaghe & 1477530 & 4497580 & 0.11 & $0.9 \pm 0.4$ \\
9 & Monte Ruju & Siligo & 1477910 & 4495680 & 0.10 & $0.6 \pm 0.1$ \\
10 & Monte Percia & Siligo & 1478320 & 4496080 & 0.04 & $0.6 \pm 0.1$ \\
11 & Monte Cuccuruddu & Cheremule & 1476520 & 4483540 & 0.12 & $0.11 \pm 0.02$ \\
12 & Monte Cujaru & Bonorva & 1486150 & 4480380 & 0.51 & $0.8 \pm 0.1$ \\
13 & Monte Annaru Poddighe & Giave & 1479240 & 4479730 & 0.69 & $>0.2$ \\
\hline
\end{tabular}

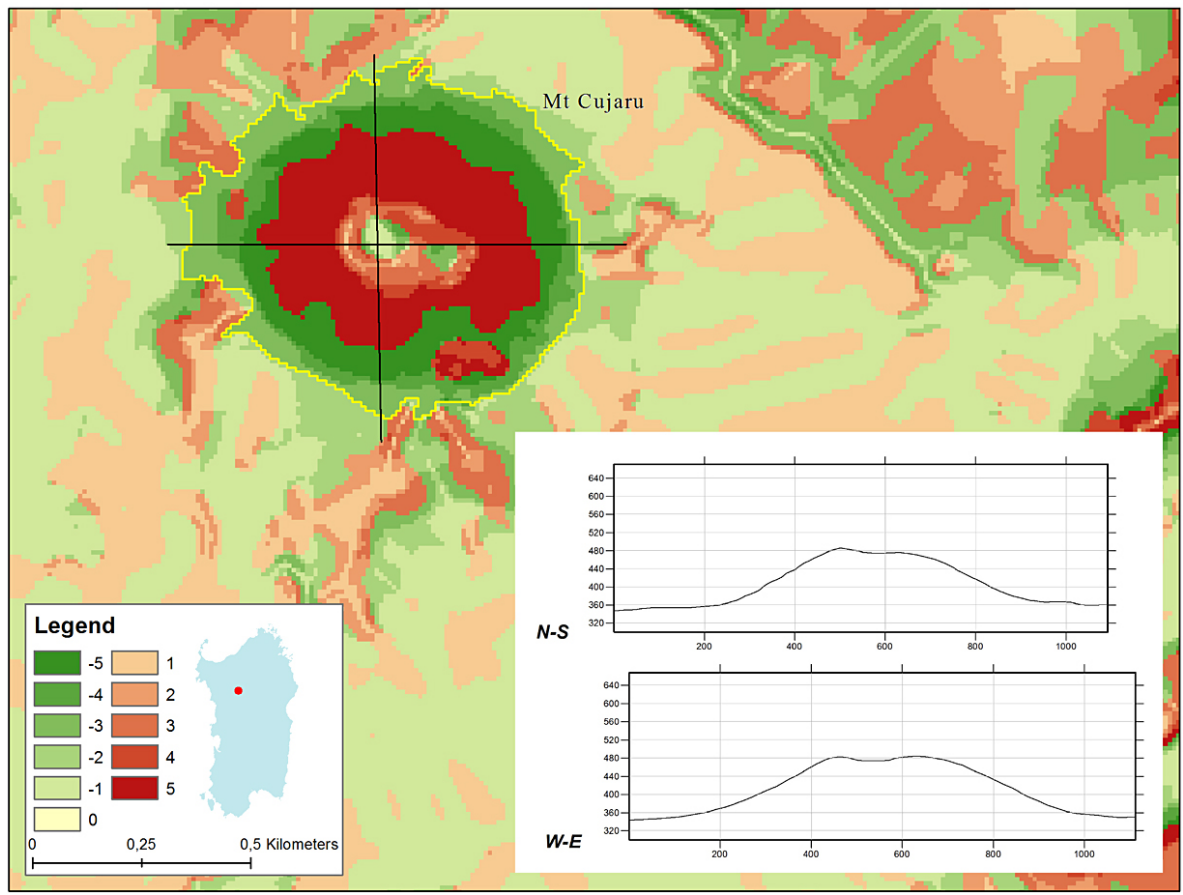

Figure 3. STC morphometric classification and topographic profiles of Mt Cujaru. The yellow line is the boundary of the volcanic edifice extracted from the transformation in polyline of the limit of the class -3 . In the map, green and red colours represent respectively concave and convex areas, with the values of slope referring to the five classes indicated in Table 2. Class 0 represents plain or horizontal areas.

the study. Based on the general assumption that the smallest object to be generated on the DEM is at least twice the size of the grid (Dikau, 1989), the $10 \mathrm{~m}$ resolution was considered satisfactory for the requested final mapping scale of $1: 25000$ (Melis et al., 2013).

A digital terrain model (DTM) generated by the Cartographic Service of RAS (Autonomous Region of Sardinia) using the 3-D Analyst and Spatial Analyst extensions of ArcGIS 10.0 (ESRI, Redmond, USA) was used. The DTM is georeferenced according to the WGS84 datum (EPSG code: 7030) and UTM projection system (Vacca et al., 2013). The "Contour_Lines" and "Elevation_Points" layers of the $1: 10000$ scale geographic database (GeoDB 10k) were used as source data. A triangulated irregular network (TIN) was generated and subsequently transformed into a regular grid format. A "NoData" value was assigned to pixels of the sea surface. 
This DEM was pre-processed to verify the quality and to correct the possible artefacts. As indicated by Reuter et al. (2009), the quality of a DEM determines the outcomes of geomorphometric analysis. The only DEM noises removed in this research were the artefacts due to wrongly coded elevation contours or due to missing contours. These errors were detected through a hillshade view, and the correction was done by assigning the correct value to the original data. The set of elevation points, available in the original database and used as ground control points during the photogrammetric restitution, was used to improve the quality of the roughness of the land surface with other elevation data rather than the contour lines alone.

\section{The geomorphometric analysis}

Different approaches based on DEM elaborations have been proposed to draw up the boundaries of volcanic edifices after their identification. The methods based on the slope-total curvature (STC) relation, as proposed for the general classification of landforms (Vacca et al., 2013), and that proposed by Grosse et al. (2012) are reviewed, and, finally, a modification of the Grosse method (GM) is proposed here, overcoming its inherent complexity and ultimately reducing the operator choices during the delimitation process.

\subsection{Slope-total curvature (STC) algorithm}

A first approach for a classification aimed at extracting the volcanic edifices as isolated landforms with respect to the surrounding landscape is based on slope and total curvature. These two geomorphometric parameters clearly highlight the presence of a concave upward break in slope, typical of the connection between the edifice and the basement (Euillades et al., 2013). This methodology simplifies those proposed by Iwahashi and Pike (2007) and by Gorini (2009) for landform classification. Slope is a suitable landform parameter in the case of monogenetic edifices, generally characterized by a simple shape often showing a radial symmetry, which clearly stands out with respect to the surrounding basement. The choice of appropriate classes of slope has to be related to the type of edifice, as it is well known that different types of volcanic edifices show different morphological and morphometric features (see for example Pike and Clow, 1981). In the scoria cones analysed in detail for this study, slope classes arising from average morphometric data presented in the literature for the same type of landforms were used.

There are several detailed studies on the morphometric characteristics of scoria cones. In order to define the main classes of slope, Fornaciai et al. (2012) presented a statistical analysis for more than 500 scoria cones of various nature and age, extracting some basic parameters whose values partly confirm and enlarge the results obtained by Woods (1980a, b):
Table 2. Slope classification.

\begin{tabular}{ll}
\hline Slope classes & $\begin{array}{l}\text { Value expressed } \\
\text { in degree }\end{array}$ \\
\hline 1 & $<3,5$ \\
2 & $3,5-6$ \\
3 & $6-13$ \\
4 & $13-18$ \\
5 & $>18$ \\
\hline
\end{tabular}

- The connection between the slope of the cone and the surrounding basement is typically around $3.5^{\circ}$.

- The minimum average gradient of a scoria cone is about $6^{\circ}$.

- The mean slope value for the large number of studied scoria cones is about $18^{\circ}$, with a standard deviation of $\pm 5^{\circ}$.

Based on the values discussed in these studies, which at a first approximation well agree with the data set of the present research, five classes of slope were used in this step of the study (Table 2).

Slope $S$ (here expressed in degrees) represents the variation of height $z$ in the two directions $x$ and $y$; it was calculated with the Horn method (Burrough and McDonell, 1998):

$S=\arctan \left(\sqrt{(\mathrm{d} z / \mathrm{d} x)^{2}+(\mathrm{d} z / \mathrm{d} y)^{2}}\right) \cdot 57.29578$.

The curvature $K$ was instead calculated with respect to a $3 \times 3$ kernel using the equation of Zevenbergen and Thorne (1987):

$K=\left(\partial^{2} Z / \partial S^{2}\right) /\left[1+(\partial Z / \partial S)^{2}\right]^{3 / 2}$,

where $Z$ is the quadratic surface calculated as

$$
\begin{aligned}
Z & =A x^{2} y^{2}+B x^{2} y+C x y^{2}+D x^{2}+E y^{2}, \\
& +F x y+G x+H y+I
\end{aligned}
$$

where the coefficients $A$ to $I$ are the nine elevation values of the nodes of the $3 \times 3$ matrix.

The values obtained are positive and negative for convex and concave forms respectively.

Final processing of classification involves the application of the product

$\mathrm{STC}=S \cdot K$

The resulted STC is a 10-class subdivision, from -5 (strongly sloping and concave areas) to +5 (strongly sloping and convex areas) with 0 (horizontal or plain areas) as the central value (Table 2). The output of this process is a 
map representing, for each pixel, the attribution to 1 of the 10 classes; Fig. 3 shows an extract of the map related to one of the selected scoria cones (Monte Cujaru).

A preliminary delimitation of the volcanic edifice is extracted on the basis of the upper limit of the class representing a concave area with a value of slope less than 6 (class -2). As discussed above, this slope threshold is considered in the literature as the minimum average gradient of a well-preserved cone.

\subsection{The Grosse algorithm and the proposed modified Grosse method}

The application of the morphometric classification based on the STC algorithm described above, however, presents some limitations, mainly due to the naturally large variability, in terms of geomorphological and volcanological setting, presented by the studied volcanic edifices. In fact, a unique slope-curvature class is hardly representative of the real basal limit of the scoria cones from Sardinia, mainly due to their different nature, age, basement geology and degree of erosion.

In order to draw up the boundaries of the volcanic edifices with different morphology and age, the approach proposed by Grosse et al. (2012) was applied. The authors suggested the use of a complex function of two parameters: slope gradient and profile curvature (Wood, 1996), based on the observation that a volcano, although bounded by a major rupture of the slope that connects the flanks of the edifice with the surrounding landscape, generally presents morphological complications that often do not allow an automatic tracing of the perimeter of its base.

The function proposed by Grosse et al. (2012) for the extraction of the boundaries of volcanic edifices, the boundary delineation layer (GM), is

$\mathrm{GM}=\mathrm{PC}_{n} f+S_{n}(1-f)$,

where $\mathrm{PC}_{n}$ and $S_{n}$ are respectively the normalized values of profile curvature and slope and $f$ is a weighting factor of the two functions with a suggested value of 0.7 (Grosse et al., 2012).

The normalized values of PC and $S$ are calculated as

$\mathrm{PC}_{n}=\left(\mathrm{PC}_{i}-\mathrm{PC}_{\min }\right) / \mathrm{PC}_{\text {range }}$,

$S_{n}=\left(S_{i}-S_{\text {min }}\right)^{2} /\left(S_{\text {range }}\right)^{2}$,

and the subscripts $i, \min$ and range respectively refer to the point value, the minimum calculated value and the maximum-minimum calculated range of curvature and slope. These values were calculated from a subregion related to each volcanic edifice, tracing the pixel profile that cuts the landform and extracting the minimum and maximum values for slope and curvature.

Assuming that the limit has a concave morphology, the peculiarity of this function is that it presents a relative minimum corresponding to the boundary between the volcanic edifice and the basement. This method is referred to here as the Grosse method 9Grosse et al., 2012).

As clearly stated by the same authors, however, the method does not discriminate locally in the case of a non-concave boundary, which could be the case when the volcanic edifice is built upon a rough, irregular basement or on top of tectonic lineaments such as faults. The authors suggest applying the function and delineating the edifice boundaries by visual interpretation of the results (i.e. "manually" tracing the path along the minimum values of the generated layer), as the main problem is in general related to the unequivocal distinction of the basement from the edifice.

We propose here a modification of the GM in order to make the edifice much more distinguishable from the surrounding basement in the DEM elaboration. This result was obtained by introducing a new function of the same parameters as GM. The proposed algorithm, hereafter referred to as modified Grosse (GMod), is

$\operatorname{GMod}=\left(\mathrm{PC}_{n} f\right) \cdot\left[S_{n}(1-f)\right]$.

In this case, where the value of one of the two parameters is low (as in the case of a nearly planar or a very gentle sloping basement), it decreases the final value, thereby strongly differentiating the basement from the rest of the edifice, which is generally characterized by high values in at least one of the two parameters.

The comparison between the resulting images obtained from GM and GMod is shown in Fig. 4. The GMod images are very appropriate to calculate the threshold for masking the area around the volcanic edifice and delineate the boundary (Fig. 5). Apart from minor local irregularities, largely deviating from the smooth circular shape characterizing scoria cones, and in which manual drawing cannot be avoided, in this way the boundary is generally clearly evidenced around most of the edifice, helping in its automatic tracing.

\section{Geological constraints}

Parallel to the geomorphometrically based delimitation process, photogeological interpretation, geological map analysis and field survey were performed in order to check and possibly correct the final results. Some general statements can be used in this case.

- Volcanic edifice boundaries cannot cross-cut nonvolcanic rocks.

- Pyroclastic edifices such as scoria cones are commonly associated to lava flows erupted from the flank or from the base of the cone.

- Scoria cone can grown on pre-existing lava fields. In this case, it is fundamental to distinguish cone-forming deposits from other volcanic products which preceded or post-dated cone formation. In general, we considered 


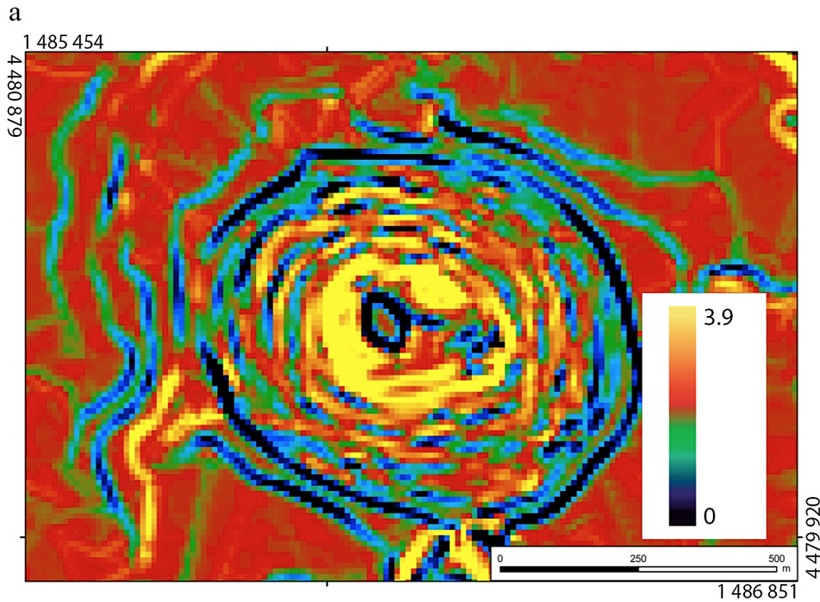

b

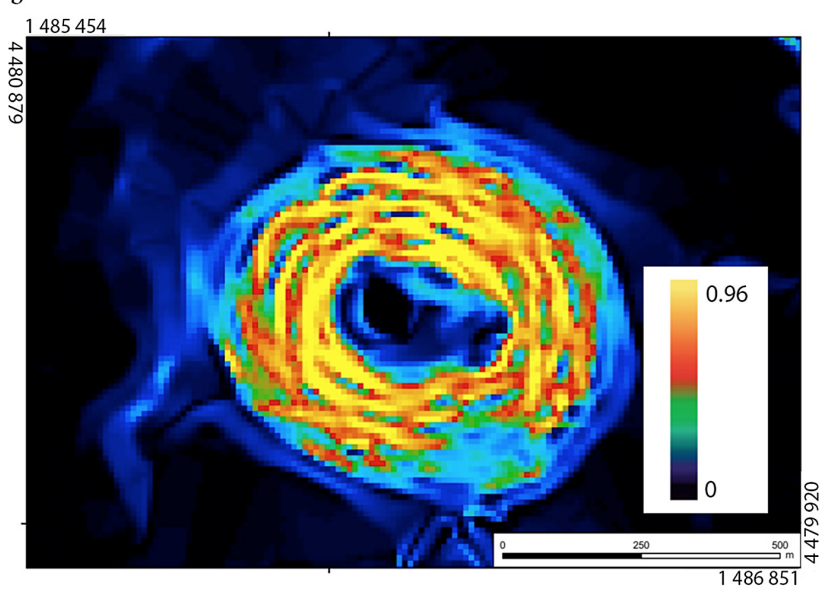

Figure 4. Comparison between the resulting image obtained with the application of the (a) Grosse method (GM) and (b) modified Grosse method (GMod) to the area of Mt Cujaru. The colour scale, from dark blue to bright yellow, indicates the range from minimum to maximum values of the resulted data. The minimum value is used for the boundary delimitation.

as an integrant part of the edifice only those deposits that lie on its flanks and are thus possibly associated with cone-related eruptive vents.

- The deposits related to gravitational processes (e.g. landslides) redistributing the primary cone deposits are here considered as part of the edifice.

- In the case of partially eroded edifices in which internal geological features and facies architecture are clearly visible, geology should represent a major constraint for delimiting the inner structure of the edifice from the partially eroded distal products.

Because the occurrence of various types of deposits can strongly reduce the efficacy of geomorphometric algorithms, we suggest that the final delimitation of the cone should always be checked against the observed geological features.

\section{Results and discussion}

The described methodological approach, based on DEM elaborations, was applied to 13 Plio-Pleistocene scoria cones from Sardinia, with the aim of tracing their boundaries. The results are first discussed with reference to two scoria cones, representative of two endmembers with different degrees of complexity of the landform and of their surroundings. Finally, the general results relative to the 13 delimited scoria cones are also briefly presented. The progressive refinement of edifice boundaries is obtained by the integrated use of the STC, the GM and the GMod algorithms; this methodology clearly shows how the introduction of the GMod algorithm strongly improves the final results.

Monte Cujaru scoria cone represents the simplest case (Fig. 3). It is a largely preserved, poorly eroded scoria cone built on a nearly planar surface, characterized by the presence of a summit crater depression, limited by a crater rim elevated about $130 \mathrm{~m}$ with respect to the base of the cone and with an average slope of the flanks of about $30^{\circ}$.

Conversely, Monte Annaru Poddighe scoria cone here represents the most complex case (Fig. 6). It is an asymmetric, cone-shaped relief elevated about $110-180 \mathrm{~m}$ above its base, mostly built on a basaltic lava plateau formed during the initial activity of the same eruptive centre. The southern flank of the scoria cone is built upon a tectonically related plateau elevated about $90-100 \mathrm{~m}$ above the surrounding basaltic plain and constituted by Miocene age marine sediments (Carmignani et al., 2008). The western flank of the scoria cone experienced a syn-eruptive partial collapse possibly related to the outward pushing of lava flowing from the base of the cone.

\subsection{STC map}

The STC map of Monte Cujaru (Fig. 3) shows an approximately concentric, sub-circular distribution of the slope classes. Deviations from circularity arise in correspondence to local irregularities, related both to minor, shallow-seated landslides and to the erosional heterogeneities of the surrounding. In the case of Monte Cujaru, the $3.5^{\circ}$ slope limit for locating the physical junction between the cone and its basement (as suggested in Fornaciai et al., 2012) is extremely irregular, as it is mainly controlled by erosional features affecting the topographic surface around the scoria cone. Instead, the $6^{\circ}$ threshold represents a good first approximation for the edifice boundary, although this limit cannot be considered definitive, due to the extremely irregular trend along the northern limit of the edifice and to minor irregularities unrelated to the constructional processes of the edifice.

The STC map of Monte Annaru Poddighe (Fig. 6) shows a discontinuous, approximately concentric, sub-circular distribution of the slope classes. Deviations from circularity affect almost all slope classes in the western sector, in proximity to the collapsed portion of the cone. Other deviations 

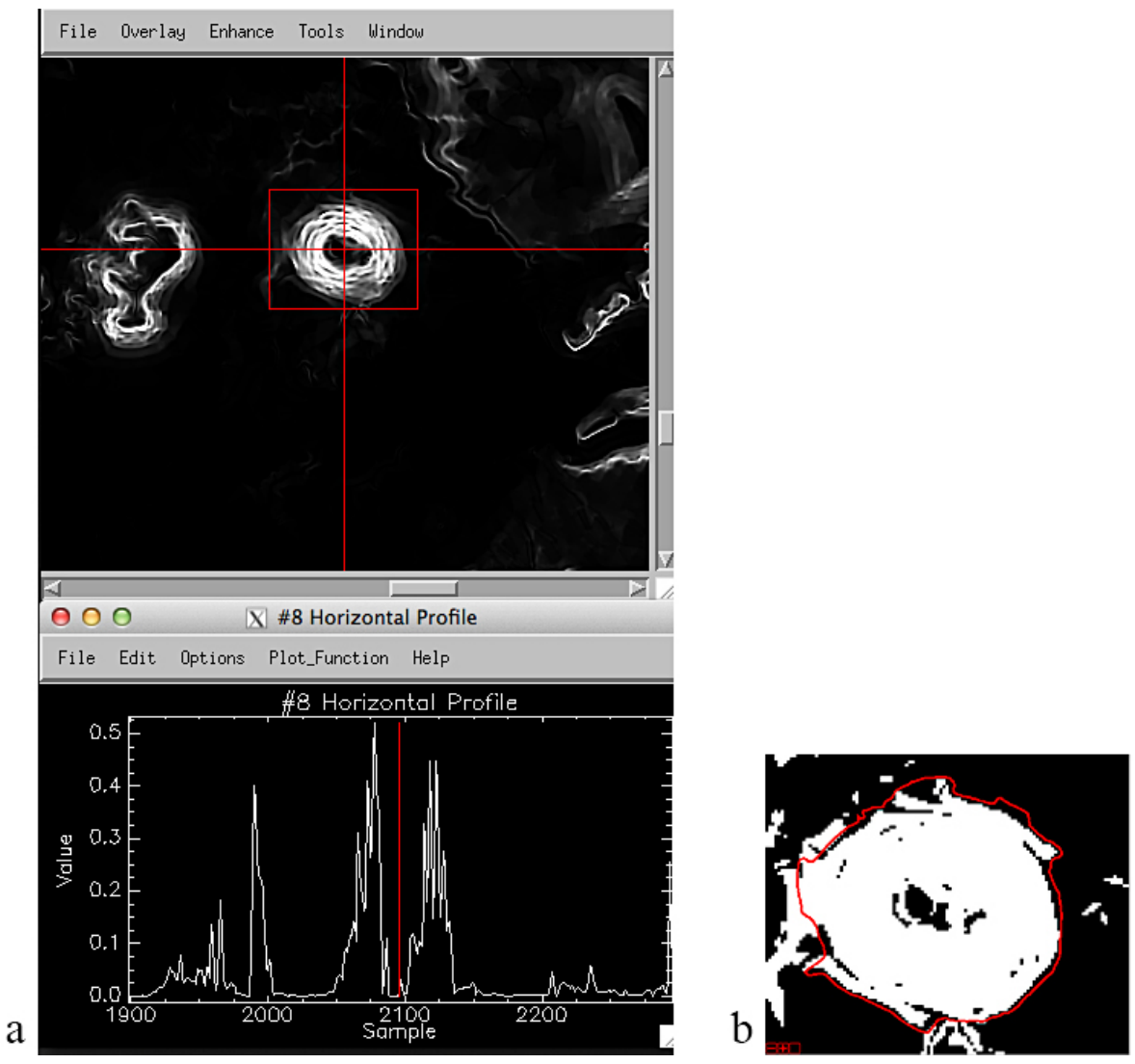

Figure 5. Application of the modified Grosse method to the DEM of Mt Cujaru: (a) the horizontal profile enhances the minimum and maximum values (thresholds) used to apply a mask to the image and to classify the data; (b) mask image ( 0 in black and +1 in white). In red the final boundary.

from circularity arise in correspondence to the $-2 /-3$ and $-3 /-4$ classes in the northern and southern flanks, in correspondence to morphological irregularities of the surrounding landscape (Fig. 6a). The $-2 /-3$ classes boundary was considered in order to approximate the outer limit of the scoria cone, although this limit, due to its discontinuous trend, cannot be extended to the entire base. The $3.5^{\circ}$ threshold in slope (here corresponding to the lower limit of the class -2) does not reflects the smooth circular morphologic nature of scoria cones (Walker, 2000).

This algorithm represents, especially in the case of a nearly regular cone-shaped edifice, a powerful tool to extract a landform from a study area, but - in both the study cases - it does not discriminate satisfactorily the volcano edifice from the basement.

\subsection{GM map}

On the flanks of the Monte Cujaru cone, the GM map (Fig. 4a) shows a regular concentric pattern of alternating sub-circular red and blue bands (in this representation), representing respectively the maximum and minimum of the normalized reference function (Eq. 5). At the base of the sco- ria cone, in the eastern sector, a wide blue band, representing the relative minimum values, largely overlaps the upper limit of class -2 from the STC processing, but overall this band cross-cuts different slope classes, smoothing many irregularities which characterize the STC-based delimitation.

The GM algorithm applied to the more complex case of Monte Annaru Poddighe shows a similar concentric subcircular pattern (Fig. 6b). A main blue band well delimitates the base of the cone in the NE sector. Conversely, an important deviation from circularity arises in the southern sector, where the blue bands outline the shape of the surrounding plateau formed by Miocene sediments, and in the NNW sector, where the main blue band marking the base of the edifice in the NE sector shows an irregular, rough trend and progressively departs from the edifice base toward the east.

As suggested by Grosse et al. (2012), the blue band can be used to manually trace the edifice boundary, but some doubts still remain due to discontinuity of this band and to the local occurrence of close multiple minima also in the simplest case. Moreover, several blue-green bands cross-cut the planar topography close to the edifice, highlighting minor topographic irregularities and making the visual interpretation of the GM map more complex. 


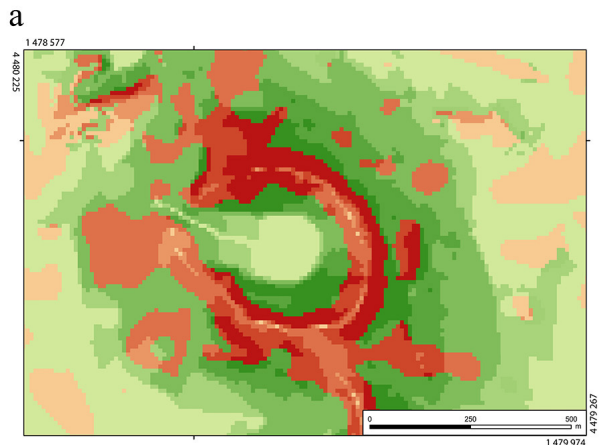

C

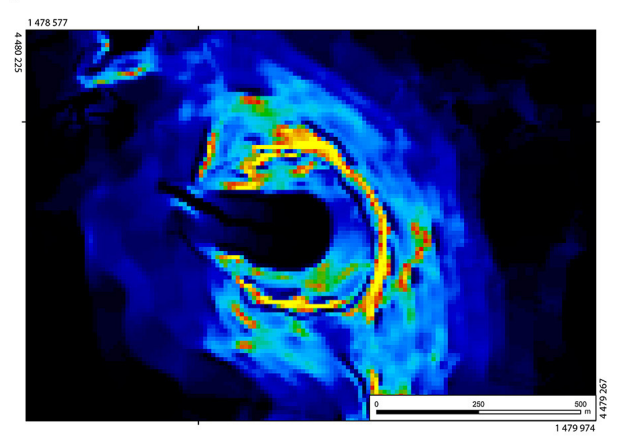

e

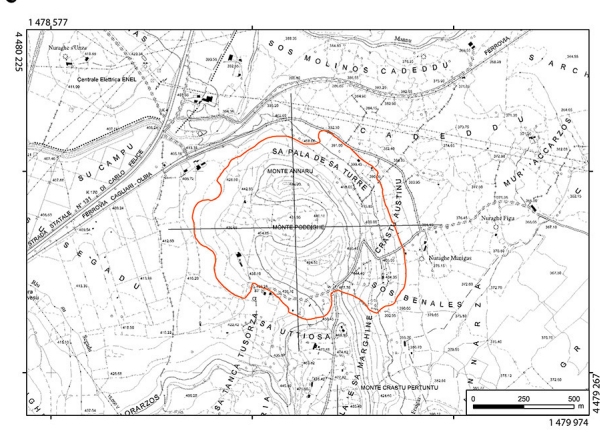

b

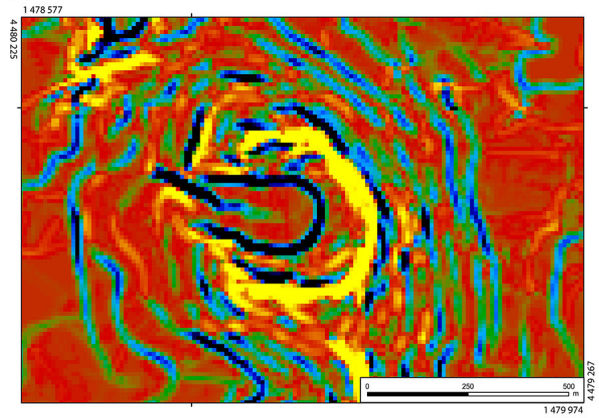

d



$\mathrm{f}$


Figure 6. Mt Annaru Poddighe: (a) first morphometric classification (legend in Fig. 3); (b) Grosse method (legend in Fig. 4); (c) modified Grosse method (legend in Fig. 4); (d) geological map; (e) topographic map with the final boundary in red, illustrating the traces; and (f) topographic profiles of the volcanic edifice.

\subsection{GMod map}

To avoid the problems arising from the STC and GM methods and to reduce the dependency from a subjective, operator-driven selection of the edifice boundary, and to improve the accuracy of the results, the GMod algorithm was also applied.

The GMod map of the regular edifice of Monte Cujaru (Fig. 4b) shows a concentric pattern of bands on the flanks of the edifice, and blue scale near concentric irregular-shaped bands in the base zone. The boundary delineation layer in the plain surrounding the edifice has a low and poorly variable value (represented by the black colour in Fig. 4b), with only minor blue zones connecting the edifice to the plain. These transitional, blue-coloured zones are cross-cut by black or dark blue narrow bands representing the minimum values. These bands largely overlap with those of the GM map but are reduced in number. At the north-eastern sector, the GM map shows three blue bands corresponding, whereas the pattern shown by the GMod map (from the inner to the outer zone) appears largely simplified. In the same way, in the south-western sector, the two bands evidenced in the GM elaboration reduce to one band and to a steady colour transition.

In the more complex case of Monte Annaru Poddighe, the GMod elaboration proved to be very useful, as it filters out the evident multiple minima bands of the GM data between 

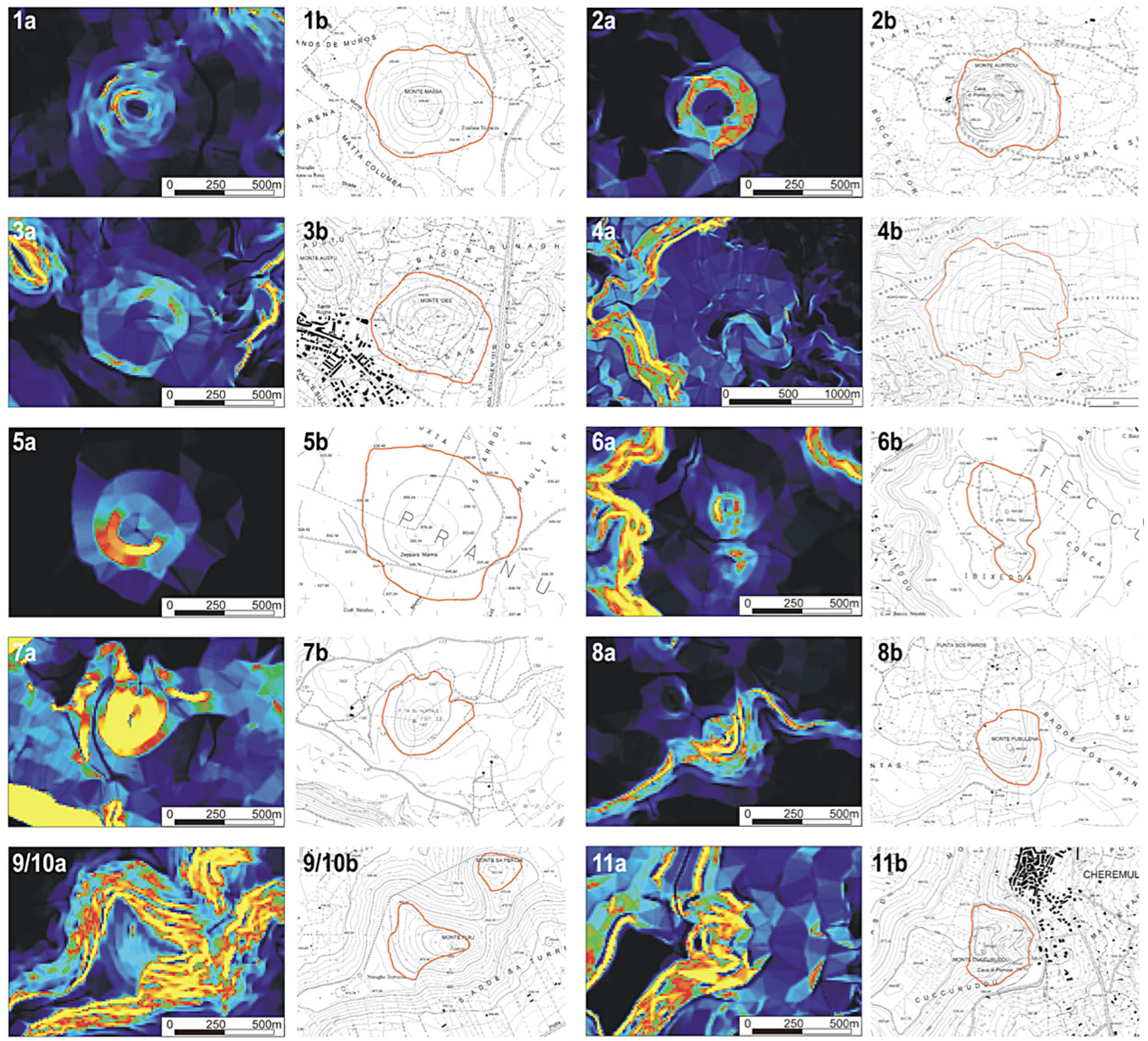

Figure 7. In this figure the applied GMod classification and the final delimitations of the boundaries are overlaid on the topographic map (see the legend in Fig. 4). The numbers of the edifices refer to Table 1.

the base of the edifice and its surroundings (Fig. $6 \mathrm{~b}$ and c). In the southern sector, where the morphological features do not reflect the geological characteristics of the base of the cone and of its surroundings, the lithological contact between the Plio-Pleistocene volcanic and Miocene sedimentary rocks drives the delimitation process (Fig. 6d).

As a general rule, the GMod algorithm reduces the uncertainties related to the occurrence of several repeated minimum bands of the GM approach and presents the advantage of smoothing the morphologic irregularities of the plain surrounding the edifice, simplifying the visual interpretation of the DEM elaborations. It looks self-standing in simple cases (i.e. symmetric cone shape), allowing an automatic tracing for most of the edifice perimeter. In more complex cases, where erosion is very impactful, the geological constraints still play a prominent role in the final delimitation of the edifice.

The GMod algorithm has been also applied to 11 other scoria cones, and the resulting boundaries have been extracted to compare and integrate the geological and geomorphological observations. In Fig. 7 the applied GMod classification and the final delimitations of the boundaries are presented. The results are often an intermediate step between the endmember cases discussed above. In cases 1, 2, 4, 5 and 7 
(Fig. 7), the delimitation is mainly based on the results of the GMod algorithm. In these cases, minor deviations from the blue/black boundaries (specifically in the cases 5 and 7) arise considering the circular nature of scoria cones. In cases 3,6 , $8,9,10$ and 11 , the geology exerts major control in the delimitation process, and erosion and tectonics deeply modify the original shapes of the cones.

\section{Conclusions}

Scoria cones from Sardinia offer - due to the wide spectrum of age, erosion and constructional conditions, resulting in an extremely variable range of shapes - a suitable case study to test the efficiency of existing algorithms and for developing new algorithms aimed at the delimitation of volcanic edifices.

The obtained results, in the case of scoria cone edifices, can be summarized in the following points:

- The SCT morphometric classification well highlights the shapes of the edifices but does not precisely identify the boundary with the surrounding basement.

- The algorithm introduced by Grosse et al. (2012) performs very well in finding minima in the complex slope-curvature function but carries an intrinsic uncertainty for tracing the outer boundary of a volcanic edifice mainly due to its high sensitivity to morphological changes.

- The proposed modification of the method by Grosse (2012), based on a different function of the normalized slope and curvatures for each specific edifice, is helpful in overcoming the problem of manual final tracing of the edifice boundaries, especially in regularly shaped cones.

- In more complex shapes derived from eroded cones, geological data still play a key role in tracing the boundary of the volcanic edifices.

- As a consequence, although the presented algorithm reduces the subjectivity of tracing volcanic edifice boundary, and in agreement with that which was already stated by Evans (2012), the complete automatic delimitation of landforms still remains a research frontier.

- We suggest that the proposed method of an integrated use of opportunely processed morphometric data (STC, GM, GMod) together with detailed geological data may result in a more objective delimitation of landscape morphologies. In particular, the proposed method performs very well with a large variety of volcanic edifices, and it is probably suited for any landscape morphology clearly standing against a clearly contrasting basement.
Acknowledgements. The authors thank the Autonomous Region of Sardinia for the support in this study.

Edited by: T. Hengl

\section{References}

Beccaluva, L., Deriu, M., Macciotta, G., Savelli, C., and Venturelli, G.: Carta geopetrografica del vulcanismo Plio-Pleistocenico della Sardegna nord occidentale, Scala $1: 50$ 000, Grafiche STEP cooperativa, Parma, 1981.

Beccaluva, L., Civetta, L., Macciotta, G., and Ricci, C. A.: Geochronology in Sardinia: results and problems, Rendiconti della Società Italiana di Mineralogia e Petrologia, 40, 57-72, 1985.

Burrough, P. A. and McDonell, R. A.: Principles of Geographical Information Systems, Oxford University Press, New York, 1998.

Carmignani, L., Oggiano, G., Funedda, A., Conti, P., Pasci, S., and Barca, S.: Carta Geologica della Sardegna a scala 1:250.000, Litografia Artistica Cartografica s.r.l., Firenze, 2008.

Carn, S.: The Lamongan volcanic field, East Java, Indonesia: physical volcanology, historic activity and hazards, J. Volcanol. Geoth. Res., 95, 81-108, 2000.

Cas, R. A. F. and Wright, J. V.: Volcanic successions, modern and ancient, Allen and Unwin, London, 1987.

Dikau, R.: The application of a digital relief model to landform analysis, in: Three dimensional Application in Geographical Information Systems, edited by: Raper, J. F., Taylor \& Francis, London, 55-77, 1989.

Euillades, L., Grosse, P., and Euillades, P.: NETVOLC: An algorithm for automatic delimitation of volcano edifice boundaries using DEMs, Comput. Geosci., 56, 151-160, 2013.

Evans, I. S.: Geomorphometry and landform mapping: what is a landform?, Geomorphology, 137, 94-106, 2012.

Fink, J. H. and Anderson, S. W.: Lava Domes and coulees, in: Encyclopedia of Volcanoes, edited by: Sigurdsson, H., Houghton, B. F., McNutt, S. R., Rymer, H., and Stix, J., Academic Press, San Diego, 643-662, 2000.

Florinsky, I. V.: Digital Terrain Modeling: A Brief Historical Overview, in: Digital Terrain Analysis in Soil Science and Geology, Elsevier, Amsterdam, 1-4, 2012.

Fornaciai, A., Favalli, M., Karátson, D., Tarquini, S., and Boschi, E.: Morphometry of scoria cones, and their relation to geodynamic setting: A DEM-based analysis, J. Volcanol. Geoth. Res., 217218, 56-72, 2012.

Francis, P.: Volcanoes: A planetary perspective, Oxford University Press, Oxford, 1993.

Gorini, M. A. V.: Physiographic classification of the ocean floor: a multi-scale geomorphometric approach, in: Proceeding of Geomorphometry Conference, edited by: Purves, R., Gruber, S., Straumann, R., and Hengl, T., University of Zurich, Zurich, Switzerland, 98-105, 2009.

Grosse, P., van Wyk de Vries, B., Euillades, P. A., Kervyn, M., and Petrinovic, I. A.: Systematic morphometric characterization of volcanic edifices using digital elevation models, Geomorphology, 136, 114-131, 2012.

Grosse, P., van Wyk de Vries, B., Petrinovic, I. A., Euillades, P. A., and Alvarado, G.: Morphometry and evolution of arc volcanoes, Geology, 37, 651-654, 2009. 
Hooper, D. and Sheridan, M.: Computer-simulation models of scoria cone degradation, J. Volcanol. Geoth. Res., 83, 241-267, 1998.

Iwahashi, J. and Pike, R. J.: Automated classifications of topography from DEMs by an unsupervised nested-means algorithm and a three-part geometric signature, Geomorphology, 86, 409-440, 2007.

Kereszturi, G., Jordan, G., Németh, K., and Doniz-Paez, J. F.: Syneruptive morphometric variability of monogenetic scoria cones, Bull. Volcanol., 74, 2171-2185, doi:10.1007/s00445-012-06581, 2012.

Kereszturi, G., Geyer, A., Martí, J., Németh, K., and Dóniz-Páez, F. J.: Evaluation of morphometry-based dating of monogenetic volcanoes - a case study from Bandas del Sur, Tenerife (Canary Islands), Bull. Volcanol., 75, 734-753, 2013.

Lecca, L., Lonis, R., Luxoro, S., Melis, E., Secchi, F., and Brotzu, P.: Oligo-Miocene volcanic sequences and rifting stages in Sardinia: a review, Periodico di Mineralogia, 66, 7-61, 1997.

Lustrino, M., Melluso, L., Morra, V., and Secchi, F.: Petrology of Plio-Quaternary volcanic rocks from central Sardinia, Periodico di Mineralogia, 65, 275-287, 1996.

Lustrino, M., Melluso, L., and Morra, V.: The role of lower continental crust and lithospheric mantle in the genesis of PlioPleistocene volcanic rocks from Sardinia (Italy), Earth Planet. Sc. Lett., 180, 259-270, 2000.

Lustrino, M., Melluso, L., and Morra, V.: The transition from alkaline to tholeiitic magmas: a case study from the Orosei-Dorgali Pliocene volcanic district (NE Sardinia, Italy), Lithos, 63, 83$113,2002$.

Lustrino, M., Morra, V., Melluso, L., Brotzu, P., D’Amelio, F., Fedele, L., Lonis, R., Franciosi, L., and Petteruti Liebercknect, A. M.: The Cenozoic igneous activity in Sardinia, Periodico di Mineralogia, 73, 105-134, 2004.

Lustrino, M., Melluso, L., and Morra, V.: The geochemical peculiarity of 'Plio-Quaternary' volcanic rocks of Sardinia in the circum-Mediterranean Cenozoic Igneous Province, in: Cenozoic volcanism in the Mediterranean area, edited by: Beccaluva, L., Bianchini, G., and Wilson, M., Geological Society of America Special Paper 418, The Geological Society of America, Boulder, CO, USA, 277-301, 2007.

Mazzarini, F., Ferrari, L., and Isola, I.: Self-similar clustering of cinder cones and crust thickness in the Michoacan-Guanajuato and Sierra de Chichinautzin volcanic fields, Trans-Mexican Volcanic Belt, Tectonophysics, 486, 55-64, 2010.
Melis, M. T., Loddo, S., Vacca, A., and Marrone, V. A.: Applicazione di un metodo di analisi geomorfometrica a supporto della cartografia pedologica in Sardegna, 17a Conferenza Nazionale ASITA, Riva del Garda, Italy, 5-7, 993-1000, 2013.

Ollier, C.: Volcanoes, Blackwell, Oxford, 1988.

Pike, R. J.: Volcanoes on the inner planets-Some preliminary comparisons of gross topography, in: Lunar and Planetary Science Conference, 9th, Houston, Tex Proceedings, 3, A79-39253 1691, Pergamon Press, Inc., New York, 3239-3273, 1978.

Pike, R. J. and Clow, G. D.: Revised classification of terrestrial volcanoes and a catalog of topographic dimensions with new results on edifice volume, US Geological Survey Open-File Report OF 81-1038, US Geological Survey, USA, 1981.

Reuter, H. I., Hengl, T., Gessler, P., and Soille, P.: Preparation of DEMs for geomorphometric Analysis, in: Geomorphometry: Concepts, Software, Applications, edited by: Hengl, T. and Reuter, H. I., Elsevier, Amsterdam, 227-254, 2009.

Shary, P. A.: Land surface in gravity points classification by a complete system of curvatures, Math. Geol., 27, 373-390, 1995.

Shary, P. A., Sharaya, L. S., and Mitusov, A. V.: Fundamental quantitative methods of land surface analysis, Geoderma, 107, 1-32, 2002.

Thouret, J. C.: Volcanic geomorphology - an overview, Earth-Sci. Rev., 47, 95-131, 1999.

Tibaldi, A.: Morphology of pyroclastic cones and tectonics, J. Geophys. Res., 100, 24521-24535, 1995.

Vacca, A., Loddo, S., Melis, M. T., Funedda, A., Puddu, R., Verona, M., Fanni, S., Fantola, F., Madrau, S., Marrone, V. A., Serra, G., Tore, C., Manca, D., Pasci, S., Puddu, M. R., and Schirru, P.: A GIS based method for soil mapping in Sardinia, Italy: A geomatic approach, J. Environ. Manage., 138, 87-96, 2013.

Walker, G. P. L.: Basaltic volcanoes and volcanic systems, in: Encyclopedia of Volcanoes, edited by: Sigurdsson, H., Houghton, B. F., McNutt, S. R., Rymer, H., and Stix, J., Academic Press, San Diego, 283-290, 2000.

Wood, C. A.: Morphometric evolution of cinder cones, J. Volcanol. Geoth. Res., 7, 387-413, 1980a.

Wood, C. A.: Morphometric analysis of cinder cone degradation, J. Volcanol. Geoth. Res., 8, 137-160, 1980b.

Wood, J.: The Geomorphological Characterization of Digital Elevation Models, Ph.D. Thesis, University of Leicester, Department of Geography, Leicester, UK, 1996.

Zevenbergen, L. W. and Thorne, C. R.: Quantitative analysis of the land surface topography, Earth Surf. Proc. Land., 12, 47-56, 1987. 